\title{
Gıda ve Finans Sektöründe Çalışan Performansı Hangi Faktörlerden Etkileniyor? Sürdürülebilir Kalite Algısı, Psikolojik İyi Oluş ve Çalışmaya Tutkunluk Değişkenlerinin Rolüَ${ }^{1}$
}

\author{
DOI: 10.26466/opus.583821
}

*

Selma Arıkan* - Bilal Cankır**

* Doç. Dr, İstanbul Medeniyet Üniversitesi, Edebiyat Fakültesi, Kadıköy / İstanbul / Türkiye

E-Posta: selma.arikan@medeniyet.edu.tr

ORCID: 0000-0002-9603-8243

** Doç. Dr, İstanbul Medeniyet Üniversitesi, Siyasal Bilgiler Fakültesi, Kadıköy / İstanbul / Türkiye

E-Posta: bilal.cankir@medeniyet.edu.tr

ORCID: $\underline{0000-0001-5126-8769}$

\begin{abstract}
Öz
Örgütler için sürdürülebilir kalite sadece örgütsel verimlilik ve etkinlikle ilişkili gibi algılansa da kurum çalışanlarının sürdürülebilir kalite alğları da çalışan tutumları ve iş sonuçları gibi pek çok değişkeni etkileyebilmektedir. Bu çalışma kapsamında finans ve gıda sektöründe tam zamanl olarak çalışan toplam 659 katılımcıdan toplanan veriler ile çalışanların sürdürülebilir kalite algısı, psikolojik iyi oluşları, çalışmaya tutkunlukları ve performans arasındaki ilişkiler incelenmiştir. Veriler Çankır ve Eti'nin (2017) 13 maddelik Sürdürülebilir Kalite Algısı Ölçeği, Diener ve arkadaşlarının (2009) 8 maddelik Psikolojik L̇yi Oluş Ölçeği, Schaufeli ve arkadaşlarının (2017) 3 maddelik Çalışmaya Tutkunluk Ölçeği (UWES -3 Very Short Form) ve Kirkman ve Rosen'in (1999) 4 maddelik Performans Ölçeği kullanılarak toplanmıştır. Hipotezlerimizi test etmek için yapılan analizler neticesinde sürdürülebilir kalite algısı değişskeninin çalışanların psikolojik iyi oluşlarını anlamlı olarak açıkladığı ( $\beta: .509, p<.01)$, psikolojik iyi oluşun çalışmaya tutkunluk değiş̧enini etkilediği $(\beta: .484, p<.01)$ ve çalışmaya tutkunluk değişkeninin de çalışan performansını öngördüğ̈̈ $(\beta: 699, p<.01)$ bulunmuştur. Aracılık etkileri için yapılan analizler neticesinde de psikolojik iyi oluşun sürdürülebilir kalite algısı ve çalşmaya tutkunluk arasında, çalş̧maya tutkunluğun da psikolojik iyi oluş ve performans arasında klsmi aracı değ̈işken rolünü üstlendikleri gözlemlenmiştir. Ayrıca finans ve gıda sektörü arasında yapılan karşılaştırmalarda finans sektörü çalışanlarının hem sürdürülebilir kalite algısı $(t: 3.12, p<.01)$ hem de psikolojik iyi $(t: 2.374, p<.05)$ oluş açısından gida sektörü çalı̧anlarına göre daha düşük puanlar aldığı gözlenmiştir. Bu fark hizmet sektöründe çalı̧smanın zorluklarından kaynaklanıyor olabilir. Bulgular sürdürülebilir kalite algısının çalı̧̧an ile ilgili değiş̧kenler üzerinden performans gibi sonuç değişkenlerini etkileyebileceğini göstermektedir. Bulgular ışığında sürdürülebilir kalite algısı ve etkileri hizmet ve gıda sektörünün özellikleri çerçevesinde tartışılmıştır.
\end{abstract}

Anahtar Kelimeler: Sürdürülebilir kalite algısl; Psikolojik iyi oluş; Çalışmaya tutkunluk; Performans, Hizmet ve üretim sektörleri

\footnotetext{
${ }^{1}$ Bu çalışma Istanbul Medeniyet Üniversitesi Bilimsel Araştırma Projeleri Koordinasyon birimince desteklenmiştir. Proje NumarasI: S-BEK-2019-1502
} 


\title{
What are the Factors Affecting Employee Performance in the Food and Finance Sector? The Role of Sustainable Quality Perception, Psychological Well-being and Work Engagement Variables
}

\begin{abstract}
For the organizations, sustainable quality is not only related with organizational effectiveness but employee related variables and outcomes as well. In this study we aimed to figure out the associations among sustainable quality perceptions of employees, employee wellbeing, work engagement and performance by using the data of 659 participants from finance (317) and food (342) sectors in Turkey, Istanbul. The data was gathered by using Çankır and Eti's (2017) 13-item sustainable quality perception scale, Diener et al.'s (2009) 8-item wellbeing scale, Schaufeli et al.'s (2017) 3 item UWES-3 scale and Kirkman and Rosen's (1999) 4 item performance scale. We assumed that employee wellbeing and work engagement would act as mediators between sustainable quality perceptions and employee performance. The analysis yielded that sustainable quality perceptions predicted employee wellbeing ( $\beta: 509, p<.01)$, employee wellbeing predicted work engagement $(\beta: 484, p<.01)$ and work engagement predicted performance $(\beta: 699, p<.01)$. The results also revealed that employee wellbeing acted as a partial mediator between sustainable quality perceptions and work engagement, whilst work engagement acted as a partial mediator between wellbeing and performance. Moreover, it was found that participants from finance sector had significantly lower scores for sustainable quality perceptions $(t: 3.12, p<.01)$ and employee wellbeing $(t: 2.374, p<.05)$ compared to the food sector. The differences can be associated with the difficulties in working in a service sector vs production sector. The results signify the importance of quality related applications of the organizations for employee related variables and outcomes. The importance of sustainable quality perceptions and its implications in both service and food sectors were discussed in the light of our findings and previous literature.
\end{abstract}

Keywords Sustainable Quality Perceptions; Psychological Well-Being; Work Engagement; Performance; Service and Manufacturing Sector 


\section{Giriş}

Yönetim çalışanların ideografik amaçlarıyla organizasyonların nomotetik amaç ve hedeflerinin ahenkli olduğu bir kurum oluşturmayı amaçlayan bir faaliyet türüdür. Yönetimin başlıca gayesi örgütün varlığını sürdürmesi, sonrasında ise büyüme, etkinlik ve verimliliktir. Bu amaçlar değerler üstünde her yönetici tarafından kabullenmiş metadeğerler olarak görülmektedir (Hodgkinson, 2008'den Akt. Çankır ve Şahin, 2018). Bu çalışma, finans ve gıda sektöründe tam zamanlı olarak çalışanlardan toplanan veriler ile çalışanların sürdürülebilir kalite algısı, psikolojik iyi oluşları, çalışmaya tutkunlukları ve performansları arasında ilişki olup olmadığını ve araştırma çerçevesinde oluşturulan modelin uygunluğunu saptamayı amaçlamaktadır. Çalışma literatürde bu dört değişkeni ilk defa beraber inceleyen bir araştırma özelliğindedir. Ayrıca her bir değişkene yönelik yapılan araştırmalara yön vermesi ve her bir kavramın gelişimi açısından bu çalışmanın önemli olduğu düşünülmektedir. Ayrıca birbirinden bağımsız iki ana sektör karşılaştırılmasının hem demografik hem de yukarıda zikredilen diğer değişkenlerle incelenmesinin belirli bir ehemmiyete sahip olduğu düşünülmektedir.

\section{Literatür}

Kalite, müşteri istek ve beklentilerinin karşılanma derecesi olarak tanımlanmaktadır. Toplam kalite yönetimi (Crosby, 1979, 1984; Deming, 1986; Feigenbaum, 1983; Garvin, 1987, 1988; Groocock, 1986; Ishikawa, 1976, 1985; Juran, 1979, 1988; Oakland, 1989); süreçlere odaklanan, iç ve dış müşteri ihtiyaçlarını tanıyan ve bu ihtiyaçları analiz etme ve geliştirme için objektif verilere dönüştüren bir kalite yönetim yaklaşımıdır. Sürekli gelişim ile müşteri mutluluğunu ve tatminini temel alan bir yaşam tarzıdır (Çankır, Koçak ve Yüksel, 2012).

Sürdürülebilirlik yaklaşımı ise, bugünün insan ihtiyaçlarını, gelecek kuşakların kendi ihtiyaçlarını karşılayabilme imkânından ödün vermeden, yani insan ihtiyaçlarının sürekli bir biçimde karşılanabilmesini ve yaşam kalitesinin arttırılmasını sağlarken, dünyanın yaşam destek sistemlerinin kapasitesini aşmayacak şekilde, doğanın yenileyebileceğinden daha 
fazlasını doğadan almadan ve dünyanın sınırlarına saygı göstererek, ekonomik, çevresel ve sosyal büyümenin sınırlarının farkına varan bir toplum oluşturmak ve belirli bir gelir düzeyinin devamlılığını sağlamak amacıyla hedeflenen yaklaşım şeklidir (Bozlağan, 2005). Dünya Çevre ve Kalkınma Komisyonu (1987) sürdürülebilir büyümeyi; "bugünün ihtiyaçlarını, gelecek kuşakların da kendi ihtiyaçlarım karşılayabilme olanağından ödün vermeksizin karşılamaktır" olarak tanımlanmıştır (TÇV, 1991'den Akt. Çankır, Fındık ve Koçak, 2012).

Sürdürülebilir kalite ise söz konusu hususlarda kalitenin sürdürülebilirlik çabaları ile yürütülmesini sağlamayı hedeflemektedir. Sürdürülebilir kalite algısı, ilgili işletmede işgörenlerin işletmelerinin sürdürülebilirlik faaliyetlerine ne kadar ehemmiyet verdiklerini ve bu faaliyetlere onları ne kadar dâhil ettiklerini içerirken, örgütün toplam kalite yönetiminin gereklerini ne şekilde sağladığını algılama dereceleri olarak tanımlanmaktadır (Çankir ve Şahin, 2018a).

Pozitif psikoloji teorisi psikolojik iyi-oluşun esas dayanak noktasıdır. Pozitif psikoloji, farklı olumsuzluklarla meydana gelen faktörlerin yerine hayat kalitesini artıran etkenlerin araştıılmasını amaçlayan bir alandır (Seligman, 2002'den Akt. Çankir ve Şahin, 2018b). Bir başka tanıma göre, psikolojik güçlülük ve pozitif hisler hakkında çalışma yapılan bilim ve uygulama alanıdır (Snyder, Lopez ve Pedrotti, 2010). (Seligman \& Csikszentmihalyi, 2014'den Akt. Çankır, 2016). Çalışanların üyesi oldukları kuruma yönelik olumlu tutumunu içeren sürdürülebilir kalite algısının çalışanların memnuniyeti ve dolayısıyla psikolojik iyi oluşları üzerinde olumlu bir etkisinin olması beklenmektedir. Buna göre araştırmanın ilk hipotezi " $\mathrm{H}_{1}$ : Sürdürebilir kalite algısı çalışanın psikolojik iyi oluş halini yordar" şeklinde oluşturumuştur.

Çalışmaya tutkunluk (work engagement) da psikolojik iyi-oluş gibi pozitif psikoloji kuramına dayanan bir kavramdır. Schauefeli, Salanova, González-Romá ve Bakker (2002) çalışmaya tutkunluğu; canlılık, adanmışlık ve çalışmaya odaklanma özellikleriyle beraber iş ile ilgili olumlu ve tatmin veren bir zihinsel durum olarak tanımlamaktadır (Çankır, 2016). Çalışmaya tutkunluk canlılık, adanmışlık ve odaklanma boyutlarını içermektedir. Çalışanların yaptığı işe ve çalıştıkları kuruma yönelik olumlu tutumlarından etkilenen ve motivasyonu artıran bir değişken olan çalış- 
maya tutkunluğun, çalışanlar için önemli bir kişisel kaynak olan psikolojik iyi oluş değişkeninden de pozitif bir biçimde etkilenmesi beklenebilir. Bu bağlamda araştırmanın ikinci hipotezi de " $\mathrm{H}_{2}$ : Çalışanların psikolojik iyi oluşları çalışmaya tutkunluk düzeylerini yordar" şeklindedir.

Performans, bireyin görevinde ne yapması gerektiğine ilişkin beklentilerle, gerçekte ne yaptığı arasındaki bağın bir fonksiyonu biçiminde tanımlanabilmektedir (Başaran, 2000). İş performansı, resmi olarak, çalışılan yerin amaç ve hedeflerine pozitif ya da negatif katkıda bulunan çalışan davranışları olarak ifade edilmektedir (Campbell, 1990'dan Akt. Colquitt, Lepine ve Wesson, 2011). Performans ise herhangi bir olgu veya duruma ulaşma arzusu ve kudreti olarak tanımlanmaktadır (Çankır ve Semiz-Çelik, 2018). Çalışan ile ilgili performansı etkileyen en önemli değişkenler çalışanın yeteneği ve işine yönelik motivasyonudur. Çalışanın işine yönelik tutumu ve motivasyonu ile bağlantılı önemli bir değişken olan çalışmaya tutkunluk performansı olumlu yönde yordamaktadır (Bakker ve Bal, 2010). Literatürde yer alan bu bilgiler ışığında araştırmanın diğer hipotezleri de şu şekilde kurgulanmıştır: "H3: Çalışmaya tutkunluk çalışanın performansını yordar", "H4: Sürdürülebilir kalite algısı ve çalışmaya tutkunluk arasındaki ilişkide psikolojik iyi oluş aracı değişkendir", "H5: Çalışmaya tutkunluk ile performans arasındaki ilişkide psikolojik iyi oluş aracı değişkendir".

\section{Yöntem}

\section{Katılımcılar}

Araştırmaya 317 tanesi finans 342 tanesi de gida sektöründe olmak üzere, tam zamanlı olarak çalışan, toplam 659 kişi katılmıştır. Katılımcıların 380 tanesi erkek, 279 tanesi kadındır. Kurum içindeki pozisyon dağılımlarına göre katılımcıların 94 tanesi üst düzey yönetici, 182 tanesi orta ve alt kademe yönetici, 383 tanesi de uzman seviyesinde olduğunu belirtmiştir. Genel dağılıma bakıldığında katılımcıların çoğunluğunun çalıştıkları kurumda 3 yıldan daha fazla deneyime sahip oldukları ve \%80'inin de 40 yaş altında olduğu gözlenmiştir. 


\section{Veri Toplama Araçları}

Demografik Bilgiler Formu: Katılımclların yaş, cinsiyet, eğitim, iş tecrübesi, pozisyon ve sektör gibi demegrafik bilgilerini elde etmek için demografik bilgi formu kullanılmıştır. Katılımcılar kendilerine kategorik olarak verilen bilgiler arasında kendi durumlarına uyan bilgileri seçerek demografik bilgi formunu doldurmuşlardır.

Sürdürülebilir Kalite Algısı Ölçeği: Çalışanların sürdürülebilir kalite alg1sını ölçmek için Çankır ve Eti (2017) tarafından geliştirilen 13 maddelik Sürdürülebilir Kalite Algısı Ölçeği kullanılmıştır. Ölçek çalışanların genel olarak kaliteli bir organizasyonda olması gereken özellikleri değerlendirmelerini sağlayan ifadelerden oluşmaktadır. Ölçekteki ifadelere örnek olarak "İşletmede başarıyı artırmak için yönetici ve çalışanlar iş birliği içinde çalışır" ve "Kaliteli bir işletmede sürdürülebilirliğin sağlanması için maddi kaynaklar tasarruflu bir şekilde kullanılır" maddeleri verilebilir. Katılımclar ölçekteki her bir ifadeye ne düzeyde katıldıklarını beşli Likert Skalasına göre değerlendirmişlerdir (1 Kesinlikle Katılmıyorum - 5 Kesinlikle Katılıyorum). Ölçeğe yapılan iç tutarlılık analizi sonucunda Cronbach $\alpha$ değeri .95 olarak bulunmuş olup bu değer ölçeğin iç güvenirliğinin yeterli olduğunu göstermektedir.

Psikolojik İyi Oluş Ölçeği: Çalışanların iyi oluş düzeylerini değerlendirebilmek için Diener ve arkadaşları (2019) tarafından geliştirilen ve 8 maddeden oluşan Psikolojik İyi Oluş Ölçeği (Psychological Wellbeing Scale) kullanılmıştır. Ölçeğin Türkçe adaptasyonu, geçerlik ve güvenirlik çalışması Telef (2013) tarafından yapılmıştır. Telef (2013) ölçek ile ilgili çalışmada 7'li skala kullanmıştır. Ölçekteki maddelere örnek olarak “Geleceğim hakkında iyimserim" ifadesi örnek olarak verilebilir. Bu araştırma kapsamında katılımcılar ölçek maddelerini okuyarak kendilerine maddelerdeki ifadelerin uyum derecelerini "1- Kesinlikle Katılmıyorum" ifadesinden "5-Kesinlikle katılıyorum" ifadesi arasında değişen beşli Likert skalasinda değerlendirmişlerdir. Ölçeğe yapılan iç tutarlılık analizinde Cronbach $\alpha$ değeri .90 bulunmuştur. 
Çalışmaya Tutkunluk Ölçeği (Çok Kısa Form): Çalışanların çalışmaya tutkunluk düzeylerini tespit etmek için Schaufeli, Schimazu, Hakanen, Salanova ve De Witte (2017) tarafından geliştirilen UWES-3 (Utrecht Work Engagement Scale Very Short Form / Utrecht Çalışmaya Tutkunluk Ölçeği Çok Kısa Formu) kullanılmıştır. Bu ölçek daha önce 17 maddelik uzun form ile 3 alt boyutlu olarak ölçülen ve ardından 9 maddelik kısa forma indirgenen UWES-17 ve UWES-9 ölçeklerinin en kısa halidir. Ölçeğin Türkçe uyarlanması Çankır ve Şahin (2018) tarafından geliştirilmiştir. Ölçek maddelerine örnek olarak "İşimde enerji dolu olduğumu hissediyorum." verilebilir. Çalışmamız kapsamında katılımcılar ölçeği beşli Likert skalasına göre değerlendirmişlerdir ve ölçeğin iç tutarlılık katsayısı hesaplandığında da Cronbach $\alpha$ değeri .86 bulunmuştur.

Performans Ölçeği: Çalışanların performansları ile ilgili algılarını değerlendirmek için Kirkman ve Rosen (1999) tarafından geliştirilen 4 maddelik performans ölçeği kullanılmıştır. Ölçek maddelerine örnek olarak "Görevlerimi tam zamanında tamamlarım." ifadesi verilebilir. Çalışmamız kapsamında katılımcllar her bir ölçek maddesini beşli Likert skalasına göre kendi performanslarını dikkate alarak değerlendirmişlerdir. Ölçeğin Cronbach $\alpha$ katsayısı .87 olarak bulunmuştur.

\section{İşlem}

Araştırma verileri anket yöntemi kullanılarak internet üzerinden araştırma linki katılımcılara gönderilerek toplanmıştır. Katılımcılara araştırmanın kapsamını belirten bir ön bilgilendirme formu ile birlikte anketin bulunduğu sayfanın bağlantısı gönderilmiş ve çalışmaya katkıda bulunmak isteyen katılımcılar ilgili bağlantıyı tıklayarak anketin bulunduğu web adresine ulaşmışlar ve sorulara cevap vermişlerdir.

\section{Verilerin Analizi}

Araştırma bulgularını tespit etmek ve hipotezleri test etmek için IBM SPSS Statistics 22 programı kullanılmıştır. Araştırma için toplanan veriler parametrik istatistik testlerini uygulamak için gerekli şartları sağlamaktadır. 
Katılımcıların demografik bilgileri için frekans analizi yapılış, araştırmadaki her bir ölçeğin iç tutarlıklık analizleri Cronbach $\alpha$ katsayısı hesaplanarak bulunmuştur. Ardından araştırma kapsamında incelenen değişkenlerin kendi aralarındaki ilişkilerini tespit etmek için Pearson's r korelasyon analizi uygulanmıştır. Daha sonra araştırma hipotezleri basit, çoklu ve hiyerarşik regresyon yöntemleri ile test edilmiştir. Çalışmaya Tutkunluk ve psikolojik iyi oluş değişkenlerinin sürdürülebilir kalite algısı ve performans arasında aracılık rollerinin değerlendirilmesinde Baron ve Kenny (1986) tarafından önerilen yöntem dikkate alınmış, ayrıca bu değişkenlerin aracılık etkisi ve bağımsız değişkenin bağımlı değişken üzerindeki dolaylı etkileri Sobel Testi ile sınanmıştır. Araştırma modeli aynı zamanda AMOS 20 kullanılarak Yapısal Eşitlik Modellemesi ile de test edilmiştir. Finans ve gıda sektörü çalışanları arasında araştırma değişkenleri açısından farklılık olup olmadığı da bağımsız örneklemler için t-testi analizi yapılarak değerlendirilmiştir.

\section{Bulgular}

Araştırma hipotezlerini test etmeden önce değişkenler hakkında genel bilgi edinmek için değişkenlerin ortalama ve standart sapma değerleri hesaplanmış ve değişkenlerin kendi aralarındaki ilişkiler Pearson's r korelasyon analizi ile test edilmiştir. Tablo 1'de değişkenlerin ortalama değerleri 5 puan üzerinden hesaplanarak standart sapma değerleri ile birlikte verilmiştir. Korelasyon analizleri neticesinde de hipotezler ile uyumlu olarak Sürdürülebilir Kalite Algısı, Psikolojik İyi Oluş, Çalışmaya Tutkunluk ve Performans arasında pozitif yönde anlamlı ilişkiler bulunmuştur.

Tablo 1: Değişkenlerin Betimsel Analizi ve Kendi Aralarında Korelasyonları

\begin{tabular}{lllllll}
\hline Değişken & Ort $/ 5$ & Ss & SKA & PİO & ÇT & Perf \\
\hline Sürdürülebilir Kalite Algisı & 1.76 & 0,69 & 1 & & & \\
Psikolojik İyi Oluş & 2.03 & 0.73 & $.51^{* *}$ & 1 & & \\
Çalışmaya Tutkunluk & 2.13 & 0.86 & $.31^{* *}$ & $.48^{* *}$ & 1 & \\
Performans & 1.95 & 0.75 & $.37^{* *}$ & $.51^{* *}$ & $.70^{* *}$ & 1 \\
\hline
\end{tabular}

$p<.05,{ }^{* *} p<.01$ (Ort: Ortalama, Ss: Standart Sapma, SKA: Sürdürülebilir Kalite Algisı, PIO: Psikolojik İyi Oluş, ÇT: Çalışmaya Tutkunluk, Perf: Performans) 


\section{Hipotez Testlerine Yönelik Basit Regresyon Analizleri}

Araştırmanın ilk hipotezi olan " $H_{1}$ : Sürdürebilir kalite algısı çalışanın psikolojik iyi oluş halini yordar" hipotezini test etmek için uygulanan basit regresyon analizinde sürdürülebilir kalite algısındaki varyansın çalışanların psikolojik iyi oluşlarındaki varyansın \%26'sını anlamlı olarak açıkladığ 1 bulunmuştur ( $R^{2}: .26$, F: 229.755, $\beta: .509$, $\left.\mathrm{p}<.01\right)$. Daha sonra psikolojik iyi oluş değişkeninin çalışmaya tutkunluk üzerindeki yordayıcılı̆̆ 1 da basit resresyon analizi ile test edilmiş ve " $\mathrm{H}_{2}$ : Çalışanlarm psikolojik iyi oluşları çalışmaya tutkunluk düzeylerini yordar" hipotezi de doğrulanmıştır $\left(\mathrm{R}^{2}: 23\right.$, $\mathrm{F}: 201.035, \beta: .484, \mathrm{p}<.01)$. Ayrıca " $H_{3}$ : Çalışmaya tutkunluk çalışanın performansin yordar" hipotezi de yapılan basit regresyon analizi sonucu doğrulanmış ( $\mathrm{R}^{2}: 49$, F:629,391, $\beta: .699$, $\left.\mathrm{p}<.01\right)$ ve çalışmaya tutkunluğun performanstaki varyansın \%49'unu açıkladığ ${ }_{1}$ bulunmuştur.

Tablo 2: Basit Regresyon Analizi Bulguları (Hipotez 1, 2 ve 3'e yönelik)

\begin{tabular}{lllllll}
\hline Bağımsız D. & Bağımlı D. & $\mathrm{R}^{2}$ : & $\mathrm{F}:$ & $\beta$ & $\mathrm{T}$ & $\mathrm{p}$ \\
\hline Sür. Kalite Algısı & Psikolojik İyi Oluş & .26 & 229,755 & .509 & 15,158 & .000 \\
\hline $\begin{array}{l}\text { Psikolojik } \\
\text { İyi Oluş }\end{array}$ & Çalışmaya Tutkunluk & .23 & 201,035 & .484 & 14,179 & .000 \\
\hline $\begin{array}{l}\text { Çalışmaya } \\
\text { Tutkunluk }\end{array}$ & Performans & .49 & 629,391 & .699 & 25.088 & .000 \\
\hline
\end{tabular}

\section{Aracı Değişken Hipotezlerine Yönelik Analiz Bulguları}

"H4: Sürdürülebilir kalite algısı ve çalışmaya tutkunluk arasında psikolojik iyi oluş aracı değişkendir" hipotezini test etmek için Baron ve Kenny (1986) tarafından önerilen yöntem kullanılmıştır. Bu yönteme göre öncelikle bağımsız değişken aracı değişkeni ve bağımlı değişkeni teker teker anlamlı olarak yordamalı, bağımlı değişken de aracı değişken tarafından anlamlı olarak yordanmalıdır. Daha sonra bağımsız değişken ve aracı değişkenin her ikisi birden regresyon analizine bağımsız değişkenler gibi dahil edilip çoklu regresyon analizi yapıldığı zaman bağımsız değişkenin bağımlı değişken üzerindeki anlamlı etkisi ortadan kalkıyor ve aracı değişken anlamlı olarak bağımlı değişkeni yorduyor ise aracı değişken için tam aracı 
değişkenlik durumundan bahsedilir. Söz konusu çoklu regresyon analizinde bağımsız değişkenin $\beta$ değeri azalır ise, yani bağımlı değişken üzerindeki yordayıcılık değeri düşer ise bu durumda kısmi aracılıktan bahsedilebilir. Bu nedenle öncelikle sürdürülebilir kalite algısı, psikolojik iyi oluş ve çalışmaya tutkunluk değişkenleri arasında yukarıdaki ön şartların sağlandığını görmek için basit regresyon analizleri yapılmıştır. Hipotez 1 ve Hipotez 2 doğrulandığ 1 için sürdürülebilir kalite algısının psikolojik iyi oluş, psikolojik iyi oluşun da çalışmaya tutkunluk üzerindeki açılayıc1lığı gerekli şartları sağlamaktadır. Ayrıca sürdürülebilir kalite algısı ve çalışmaya tutkunluk arasındaki ilişki de basit regresyon analizi ile incelenmiş ve sürdürülebilir kalite algısının her ne kadar açıklanan varyans düşük olsa da çalışmaya tutkunluğu anlamlı olarak yordadığı bulunmuştur $\left(\mathrm{R}^{2}: .01, \mathrm{~F}: 71,986, \beta: .314, \mathrm{p}<.01\right)$. Ardından denkleme psikolojik iyi oluş da eklenmiş ve psikolojik iyi oluş değişkeninin eklenmesi ile sürdürülebilir kalite algısının beta değerinin azaldığı gözlemlenmiştir. Bu durum tam aracılık etkisini göstermektedir. Bu durumu teyit etmek için yapılan Sobel Testi analizinde de psikolojik iyi oluş değişkeninin sürdürülebilir kalite algısı ve çalışmaya tutkunluk arasında kısmi aracı değişken olduğu teyit edilmiştir (Sobel:9,009, Sh:.03, p:000). Bu bulgular Tablo 3'te de ayrıntılariyla sunulmuştur.

Tablo 3: Psikolojik İyi Oluş Değişkeninin Sürdürülebilir Kalite Algısı ve Çalışmaya Tutkunluk Arasındaki Kısmi Aracılık Rolï

\begin{tabular}{lllllll}
\hline Bağımsız D. & Bağımlı D. & $\mathrm{R}^{2}$ : & $\mathrm{F}:$ & $\beta$ & $\mathrm{T}$ & $\mathrm{p}$ \\
\hline Sür. Kalite Algısı & $\begin{array}{l}\text { Çalışmaya } \\
\text { Tutkunluk }\end{array}$ & .01 & 71,986 & .314 & 8,484 & .000 \\
& $\begin{array}{l}\text { Çalışmaya } \\
\text { Tür Kalite Algınluk }\end{array}$ & .24 & 103,870 & .092 & 2,317 & .021 \\
& & & & .437 & 11,066 & .000 \\
\hline Psikolojik İyi Oluş & 9,009 & S. hata: & .03 & & & .000 \\
\hline Sobel Testi: & & & & & & \\
\hline
\end{tabular}

"H5: Çalışmaya tutkunluk ile performans arasında psikolojik iyi oluş aracı değişkendir" hipotezini test etmek için de yukarıda açıklanan basamaklar uygulanmıştır. Zaten $\mathrm{H}_{2}$ ve $\mathrm{H}_{3}$ doğrulandığı için bağımsız değişkenin arac1 değişkeni, aracı değişkenin de bağımlı değişkeni yordaması şartı sağlanmaktadır. Psikolojik iyi oluşun performans üzerindeki etkisini test etmek 
için yapılan analizde psikolojik iyi oluşun performansı anlamlı olarak öngördüğü bulunmuştur ( $\left.\mathrm{R}^{2}: .26, \mathrm{~F}: 232,096, \beta: .511, \mathrm{p}<.01\right)$. Ardından analize aracı değişken özelliğini anlamaya çalıştı̆̆ımız çalışmaya tutkunluk değişkeni de eklenmiştir ve çoklu regresyon analizi yapılarak hem psikolojik iyi oluşun hem de çalışmaya tutkunluğun performans değişkenini anlamlı olarak açıkladığı bulunmuştur ( $\left.\mathrm{R}^{2}: .53, \mathrm{~F}: 367,008, \mathrm{p}<.01\right)$. Ancak tek başına denklemde iken $\beta$ değeri. .511 olan psikolojik iyi oluş değişkeninin $\beta$ değeri .225'e düşmüştür ve regresyon denkleminde $.591 \beta$ değeri ile çalışmaya tutkunluk değişkeni performans değişkeni üzerinde daha güçlü bir yordayıcllığa sahiptir. Bu durumda çalışmaya tutkunluk değişkeni psikolojik iyi oluş ve performans arasında kısmi aracı değişken gibi gözükmektedir. Sobel Testi ile bu ilişkide çalışmaya tutkunluğun kısmi aracı değişken olduğu onaylanmıştır (Sobel:11,408, Sh:.03, p:000).

Tablo 4: Çalışmaya Tutkunluk Değişkeninin Psikolojik İyi Oluş ve Performans Arasındaki Kısmi Aracılık Rolï

\begin{tabular}{lllllll}
\hline Bağımsız D. & Bağımlı D. & $\mathbf{R}^{2}$ : & F: & $\boldsymbol{\beta}$ & $\mathbf{T}$ & $\mathbf{p}$ \\
\hline Psikolojik İyi Oluş & Performans & .26 & 232,096 & .418 & 15,235 & .000 \\
\hline Psikolojik İyi Oluş & Performans & .53 & 367,008 & .225 & 7,343 & .000 \\
\hline Çalışmaya Tutkunluk & & & & .591 & 19,265 & .000 \\
\hline Sobel Testi: & 11,408 & S. hata: & .03 & & & .000 \\
\hline
\end{tabular}

\section{Araştırma Modelinin Yapısal Eşitlik Modeli ile Test Edilmesi}

Araştırma modeli yukarıdaki kısmi aracılık bulgularını da dikkate alınarak AMOS 20 programında Yapısal Eşitlik Modellemesi kullanılarak test edilmiştir. Yapılan analiz neticesinde yukarıdaki analizler ile uyumlu olan modelin araştırma verisi ile iyi uyum gösterdiği gözlemlenmiştir (X2:700,364, CMIN/DF:2,110, GFI:0.93, TLI:0,964, CFI:0,968, RMSA:0,041, SRMR:0,037). Uyum indekslerinden 0,93 değerine sahip olan GFI modelin kabul edilebilir uyum sinırları içinde olduğunu gösterirken, diğer uyum indeksleri veri ve model arasındaki uyumun iyi olduğunu göstermektedir. Çünkü YEM literatürüne (Schumacker ve Lomax, 2010) göre TLI, CFI, ve GFI değerlerinin 0.95 'ten büyük olması veri ile model arasındaki uyumun iyi, 0.90 ile 0.95 arasında olması da kabul edilebilir olduğunu göstermektedir. Ayrıca SRMR ve RMSA değerlerinin de 0.05 'ten küçük, CMIN 
/DF'in de 3'ten küçük değerlere sahip olması uyumun iyi olduğunun göstergeleridir. Modeldeki değişkenler arasındaki ilişkileri gösteren yol tabloları Tablo 5'te sunulmuştur.

Tablo 5: Yapısal Eşitlik Modellemesinde Maksimum Olabilirlik Çıkarımı Sonuçlarına Göre İlişkiler

\begin{tabular}{lllll}
\hline Yollar & & $\begin{array}{l}\text { Standart } \\
\text { Olmayan K. }\end{array}$ & S.Hata & $\begin{array}{l}\text { Standart } \\
\text { Katsayılar }\end{array}$ \\
\hline Sür. Kalite Alg1sı $\rightarrow$ & Psiko. Iyi Oluş & $.568^{* * *}$ & .046 & $.557^{* * *}$ \\
Psikolojik İyi Oluş $\rightarrow$ & Çalış. Tutkunluk & $.538^{* * *}$ & .055 & $.518^{* * *}$ \\
Sür. Kalite Alg1sı $\rightarrow$ & Çalıs. Tutkunluk & .050 & .049 & .047 \\
Çalış. Tutkunluk $\rightarrow$ & Performans & $.588^{* * *}$ & .045 & $.658^{* * *}$ \\
Psikolojik İyi Oluş $\rightarrow$ & Performans & $.164^{* * *}$ & .042 & $.177^{* * *}$ \\
Sür. Kalite Algısı $\rightarrow$ & Performans & $.074^{*}$ & .035 & $.078^{*}$ \\
\hline
\end{tabular}

${ }^{*} p<.05,{ }^{* *} p<.01,{ }^{* * *} p<.001$

Veri ile uyumlu olan model, standart ilişki katsayıları ile birlikte Şekil 1 'de bilgilerinize sunulmuştur.

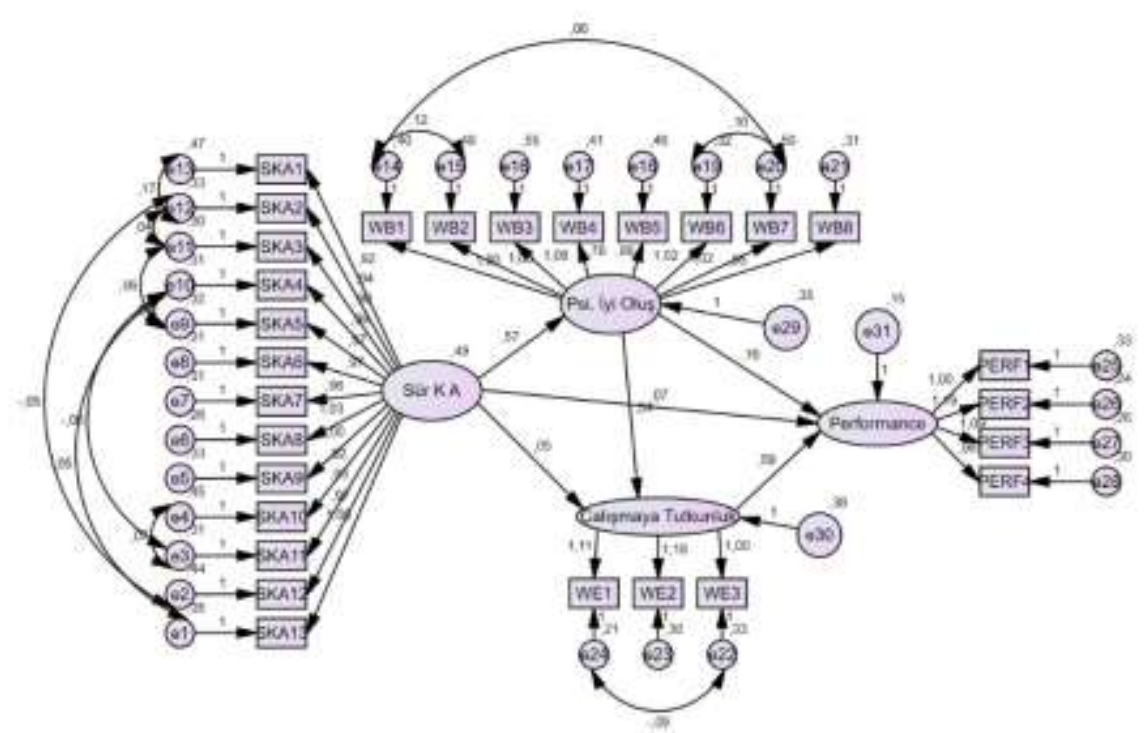

Şekil 1: Yapısal Eşitlik Modellemesine Göre Araştırmadaki Değişkenler Arasındaki İlişkiler 


\section{Gıda ve Finans Sektörünün Karılaştırmasına Yönelik Analizler}

Araştırmamız kapsamındaki değişkenlerin gıda veya finans sektöründe istihdam edilme açısından bir farklılık gösterip göstermediğine yönelik bağımsız örneklemler için t-testi analizleri yapılmıştır. Yapılan analizler neticesinde finans sektöründe çalışan katılımcıların gıda sektöründe çalışan katılımcılara göre sürdürülebilir kalite algısı (t657: $-3.117, \mathrm{p}<.01$ ) ve psikolojik iyi oluş (t643,35:-2,355, p<.05) ölçeklerinden anlamlı olarak daha düşük puan aldıkları bulunmuştur. Bulgular Tablo 6'da sunulmuştur.

Tablo 6: Gıda ve Finans Sektörü Çalışanları Arasındaki Farklar

\begin{tabular}{lllll}
\hline Bağımlı Değişken & Sektör & $\mathbf{t}$ & Ortalama & Standart Sapma \\
\hline \multirow{2}{*}{ Sürdürülebilir Kalite Algısı } & Finans & $-3,117^{* *}$ & 1,67 & 0,63 \\
& Gıda & & 1,84 & 0,73 \\
\hline \multirow{2}{*}{ Psikolojik İyi Oluş } & Finans & $-2,355^{*}$ & 1,96 & 0,64 \\
& Gida & & 2,09 & 0,80 \\
\hline
\end{tabular}

${ }^{*} \mathrm{p}<.05,{ }^{* *} \mathrm{p}<.01$

\section{Sonuç ve Tartışma}

Genel olarak araştırma bulgularına baktığımızda sürdürülebilir kalite algısına yönelik değişkenlerin çalışan ile ilgili diğer değişkenler üzerinde anlamlı olarak etkili olduğu ve araştırma hipotezlerimizin desteklendiği görülmektedir. Sürdürülebilir kalite algısı hem direkt ve hem de psikolojik iyi oluş değişkeni üzerinden dolaylı olarak çalışmaya tutkunluk değişkeni ile ilişkilidir. Aynı zamanda çalışanların psikolojik iyi oluş düzeyleri de performansı hem doğrudan hem de çalışmaya tutkunluk değişkeni üzerinden etkilemektedir. Bu bulgular literatürde daha önce yapılan çalişmalar ile de (Shimazu ve Schaufeli, 2009; Rich, Lepine ve Crawford, 2010; Christian, Garza ve Slaughter, 2011; Brunetto ve arkadaşları, 2012; Shimazu ve arkadaşları, 2015; Breevaart ve arkadaşları, 2015) uyumludur.

Performans ve onu önceleyen psikolojik iyi oluş ve çalışmaya tutkunluk gibi çalışan ile ilgili olumlu değişkenler açısından sürdürülebilir kalite algısı önemli bir değişken olarak dikkat çekmektedir. Bu bulgular örgütlerin yapmış oldukları kalite çalışmalarının sadece üretkenlik ve verimlilik üzerinde etkili olmadığını aynı zamanda çalışanlar üzerinde de olumlu 
etkiye sahip olabileceğini göstermektedir. Tabii ki pek çok çalışan müşterilerini memnun etmek, mal ve hizmet üretiminde sürekli gelişmek, yönetim süreçlerinde kaliteyi sağlamak gibi temel ilkeleri benimsemiş ve bunların devamlılığını sağlamaya çalışan bir organizasyonun parçası olmaktan memnun olacak ve böyle bir organizasyonun parçası olduğu için mutlu olacaktır. Dolayısıyla, işgörenlerin, kendilerini psikolojik olarak iyi hissetmeleri, çalışmaya tutkun olmaları ve yüksek iş performansı sergilemeleri ile yakından ilişkilidir. Bu nedenle yöneticilerin, çalışanların psikolojik olarak kendilerini iyi hissetmelerini sağlayacak örgüt ortamı oluşturmaları önemlidir.

Araştırma kapsamında çalışmamıza konu olan temel değişkenler aç1sından finans ve gıda sektörü açısından anlamlı bir farklılık olup olmadığına da bakılmıştır. Yapılan analizlerde hizmet sektörünü temsil eden finans sektörü çalışanları ve üretim sektörünü temsil eden gıda sektörü çalışanları arasında sürdürülebilir kalite algısı ve psikolojik iyi oluş değişkenleri açısından anlamlı farklar bulunmuştur. Finans sektöründe çalışan katılımcılar hem sürdürülebilir kalite algısı hem de psikolojik iyi oluş aç1sından gıda sektöründe çalışan katılımcılara göre anlamlı olarak daha düşük puanlar almışlardır. Çalışmaya tutkunluk ve performans açısından ise böyle bir farklılık bulunmamıştır. Sürdürülebilir kalite algısındaki farkl1lık Türkiye'deki finans sektörünün yapısı ile bağlantılı olabilir. 2001 yılında yaşanan ekonomik kriz öncesine göre bankalar yapısal olarak çok daha sağlam durmaya çalışsalar da finans sektörü gıda sektörü ile kıyaslandığında çok daha kırılgan bir sektördür. Ayrıca finans sektörü hizmet sektörünü temsil etmektedir ve finans sektöründeki kuruluşlar arasında sıkı bir rekabet bulunmaktadır. Ayrıca Türkiye'de enflasyonun 901 yıllara göre daha düşük olması nedeniyle finans sektöründeki kurumlar özellikle bankalar artık bireysel bankacılık hizmetlerine yönelmiş ve çalışanların üzerinde özellikle kredi vb. ürünlerin satışı için hedef baskıları oluşmuştur. Tabii ki kısa zamanda bu hedefleri yerine getirmeye çalışan finans sektörü çalışanlarının kalite algıları ve psikolojik iyi oluşları bu durumdan olumsuz olarak etkilenebilir. Diğer taraftan hizmet sektörü olarak nitelenebilecek finans sektöründe müşterilerin verilen servislerden memnun kalması ve güler yüzlü hizmet almaları da çok önemlidir. Bu açıdan değerlendirildiğinde duygusal emek açısından finans sektörü çalışanları gıda sektörü çalışanlarına göre daha dezavantajlı konumdadır. Yoğun 
duygusal emek harcamak da çalışanın üzerindeki stresi artırarak ve çalışan memnuniyetini azaltarak psikolojik iyi oluşu olumsuz yönde etkileyebilmektedir (Holman, Claire, ve Totterdell , 2002; Pugliesi, 1999; Zapft, 2002). İleride yapılacak araştırmalarda duygusal emek değişkeninin de modele dahil edilmesi bu konuya açıklık getirebilir.

Araştırmanın sonuçları değerlendirilirken araştırmanın kesitsel olması ve anket yöntemi kullanıldığı için bulguların ilişkisel nitelikte oldukları göz önünde bulundurulmalıdır. Ayrıca performans verileri de dahil olmak üzere tüm değişkenler için verinin çalışanlardan toplanması da araştırmanın bir sınırlılığı olarak dikkate alınmalıdır. 


\title{
EXTENDED ABSTRACT
}

\section{What are the Factors Affecting Employee Perfor- mance in the Food and Finance Sector? The Role of Sustainable Quality Perception, Psychological Well-being and Work Engagement Variables}

\author{
Selma Arıkan - Bilal Çankır \\ İstanbul Medeniyet University
}

Total Quality Management (TQM) and other quality related interventions has become popular in organizations since the end of 1990s as a result of the rise in the global competition among the organizations. Quality related interventions concerned with the improvement of applications, relations and methods in all aspects of organizational life. For instance one of the most known quality related interventions is TQM, and the main aim of TQM is to increase the satisfaction of customers via increasing the quality in all the processes of service or product generation from relations with suppliers to increasing the quality of work life for employees and workers. Employee related applications of quality related interventions are mainly shaped by participation and empowerment principles to increase employments competencies and satisfaction. TQM and other quality oriented interventions also deal with the quality of the relations and communication among the departments, employees and stakeholders of the organizations. Quality oriented interventions also give importance to the training and development of the employees. Besides increasing organizational effectiveness these interventions effect the satisfaction and well-being of the employees and shape employees' attitudes toward their organizations (Bozkurt and Arıkan, 2011). One of these quality related constructs that shapes employees' attitudes and motivation is sustainable quality perceptions of the employees. Sustainable quality perception is defined as the degree to which the employees perceive their organizations success about 
the quality related interventions and permanency and sustainability of these quality related successful applications (Çankir and Şahin, 2018a).

Wellbeing and happiness at work has become an area of interest since 1930s (Wright, Cropanzano, and Bonett, 2007) however earlier studies mainly concerned with the job satisfaction while trying to understand the happy worker hypothesis. However employee well-being is a larger construct compared to job satisfaction not only covering the work related aspect of employees' lives but overall well-being and satisfaction of employees about their lives. Employee well-being can be defined as the state of having no anxiety, uneasiness, depression, and other psychological disorders in individual's life (Ryff, 1995, p.99). Wright (2005) also defined wellbeing as the effectiveness of the psychological functions. The meaning of life, autonomy; competence, context which are three basic psychological needs according to the self-determination theory; satisfaction with life about different areas and overall life; and happiness have been also stated as indicators of well-being (Samman, 2007; Çankır and Yener, 2017, p. 228). Frederickson's (2001) Broaden and Built theory of Positive Emotions gave us insight that psychological well-being have the capacity to increase employees positive attitudes towards their work and organizations and their performance (Wright, et. al, 2007)

One of the constructs that cowers the positive attiudes and motivation of employees towards their work and organizations is work engagement. Schauefeli, Salanova, González-Romá and Bakker (2002) described work engagement as a positive and satisfying mental state including high energy and vitality, dedication and focus on work (as cited in Çankır, 2016). Work engagement is the indicator for the fact that the personnel feel themselves happy, healthy, good, and peaceful (Poon, 2013) and work-engagement is also found to be an antecedent of employee performance (Bakker, and Bal, 2010)

Work performance is formally expressed as the employee behavior that contributes positively or negatively to the goals and objectives of the workplace (Campbell, 1990, cited in Colquitt, Lepine and Wesson, 2011). Performance is defined as the desire and power to reach any event or situation that fulfills the employees organization and work related goals (Çankır and Semiz Çelik, 2018). 
In this study we tried to understand the relations among sustainable quality perceptions of employees, employees' psychological well-being, work engagement and performance. To reach this aim we gathered data from 659 participants employed in finance (317) and food (342) sectors in Turkey, İstanbul. The measurement tools that we used to measure our variables were Çankır and Eti's (2017) 13-item sustainable quality perception scale, Diener et al.'s (2009) 8-item wellbeing scale, Schaufeli et al.'s (2017) 3 item UWES-3 scale and Kirkman and Rosen's (1999) 4 item performance scale.

We expected positive relations among sustainable quality perceptions, employee wellbeing and performance. It was also expected that employee wellbeing and work engagement would act as mediators between sustainable quality perceptions and employee performance. The statistical analysis conducted showed that sustainable quality perceptions predicted employee wellbeing $(\beta: .509, \mathrm{p}<.01)$ in a positive way. Employee wellbeing was found to be predicting work engagement $(\beta: .484, p<.01)$ and work engagement was found to be predicting performance $(\beta: 699, \mathrm{p}<.01)$. The results also revealed that employee wellbeing acted as a partial mediator in the relationship between sustainable quality perceptions and work engagement. Moreover work engagement was found to be a partial mediator between wellbeing and performance. Besides these analysis in SPSS the model was also tested by using Structural Equation Modeling (SEM) by using AMOS 20 , and the proposed model showed a good fit with our data as it can be seen in Figure $1\left(\mathrm{X}^{2}: 700,364, \mathrm{CMIN} / \mathrm{DF}: 2,110, \mathrm{GFI}: 0.93\right.$, TLI:0,964, CFI:0,968, RMSA:0,041, SRMR:0,037).

The sectorial comparisons showed that participants from finance sector had significantly lower scores for sustainable quality perceptions ( $t: 3,12$, $\mathrm{p}<.01)$ and employee wellbeing $(\mathrm{t}: 2,374, \mathrm{p}<.05)$ compared to the food sector.

The differences can be associated with the difficulties in working in a service sector rather than production sector. The results once again emphasized the importance of quality related applications and interventions of the organizations for employee wellbeing and other employee related variables and outcomes. This study also shed light on the antecedents of employee performance. 


\section{Kaynakça / References}

Bakker, A. B., ve Bal, M. P. (2010). Weekly work engagement and performance: A study among starting teachers. Journal of occupational and organizational psychology, 83(1), 189-206.

Bozlağan, R. (2005). Sürdürülebilir gelişme düşüncesinin tarihsel arka planı. Sosyal Siyaset Konferanslarn Dergisi, 50, 1011-1028.

Bozkurt, T., ve Arıkan, S. (2011). Çalışma yaşamının kalitesi. (T. Bozkurt Ed.) Çalışma İlişkilerinin Evrimi, içinde (s. 191-232). İstanbul: Beta

Breevaart, K., Bakker, A. B., Demerouti, E., ve van den Heuvel, M. (2015). Leader-member exchange, work engagement, and job performance. Journal of Managerial Psychology, 30(7), 754-770.

Brunetto, Y., Teo, S. T., Shacklock, K., ve Farr-Wharton, R. (2012). Emotional intelligence, job satisfaction, well-being and engagement: explaining organisational commitment and turnover intentions in policing. Human Resource Management Journal, 22(4), 428-441.

Campbell, J. P. (1990). Modeling the performance prediction problem in industrial and organizational psychology. In (M.D. Dunnetteand, L.M. Hough. P. Alto ed.), (2nd ed.), Handbook of Industrial and Organizational Psychology, (p.687-732.), CA: Consulting Psychologists Press,

Christian, M. S., A. S. Garza ve J. E. Slaughter. (2011). Work engagement: A quantitative review and test of its relations with task and contextual performance. Personnel Psychology, 64 (1), 89-136.

Colquitt, J.,Lepine, J. A., ve Wesson, M. J. (2011). Organizational behavior: Improving performance and commitment in the workplace. McGrawHill Irwin.

Crosby, P.B. (1979). Quality is free. New York, McGraw-Hill Book Company.

Crosby, P.B. (1984). Quality without tears. New York, McGraw-Hill Book Company.

Çankır, B. ve D. Semiz Çelik (2018). Çalışan performansı ve mali performans: Pozitif ses çıkarma, psikolojik iyi- oluş ve çalışmaya tutkunluk ile ilişkileri ve otel işletmeleri örneği. İstanbul Gelişim Üniversitesi Sosyal Bilimler Dergisi, 5 (2), 54-67. 
Çankır, B. ve Eti, S. (2017). Üniversitelerde sürdürülebilirlik ve kalite: Sürdürülebilir kalite algısı ölçeği (ska-ö)'nin geliştirilmesi, geçerlik ve güvenirlik çalışması. II. Uluslararası Yükseköğretim Çalışmaları Konferansı, 12-14 Ekim, Antalya.

Çankır, B. ve Şahin, S. (2018c). Psychological well-being and job performance: the mediating role of work engagement. Hitit University Journal of Social Sciences Institute, 11(3), 2549-2560. doi: 10.17218/hititsosbil.487244

Çankır, B. (2016). Çalışmaya tutkunluk ve tükenmişliğin örgütsel vatandaşlık davranışı üzerinde etkisi ve bir uygulama. Yayınlanmamış Doktora Tezi, İstanbul Üniversitesi Sosyal Bilimler Enstitüsü, İstanbul.

Çankır, B., ve Şahin, S. (2018). Medya-Kültür ve Sanat Alanında Çalışanların Psikolojik İyi-Oluşları İle İşten Ayrılma Niyetleri Arasındaki İlişkide Çalışmaya Tutkunluğun Aracı Rolü. Uluslararası İdari ve İktisadi İncelemeler Dergisi.(17. Uik Özel Sayısı), 17, 333-346.

Çankır, B., ve Yener, S. (2017). İş'te pozitif davranış. Çizgi Kitapevi: Konya.

Çankır, B., Koçak, Ö. E., ve Yüksel, S. (2012). Eğitimde toplam kalite yönetimi. 10th International Conference on Knowledge, Economy and Management, Proceddings Book içinde (s. 842-856), 8 Kasım 2012, İstanbul.

Çankir, B., ve Şahin, S. (2018a). Sürdürülebilir kalite algısının işten ayrılma niyeti üzerindeki etkisinde iş tatmininin aracı rolü. Uluslararası İktisadi ve İdari Incelemeler Dergisi, (17. UIKK Özel Sayısı), 135-146.

Deming, W.E. (1986). Out of the crisis. Cambridge, MA, MIT Centre for Advanced Engineering Study.

Fbigenbaum, A.V. (1983). Total quality control. (3rd ed.), New York, McGraw-Hill Book Company.

Fredrickson, B. L. (2001). The role of positive emotions in positive psychology: The broaden-and-build theory of positive emotions. American psychologist, 56(3), 218-226.

Garvin, D.A. (1987). Competing on the Eight Dimensions of quality. Harvard Business Review, 65(6), 101-109.

Garvin, D.A. (1988). Managing quality. New York, The Free Press.

Groocock,J.M. (1986). The chain of quality. New York, John Wiley \& Sons. 
Holman, D., Chissick, C., ve Totterdell, P. (2002). The effects of performance monitoring on emotional labor and well-being in call centers. Motivation and Emotion, 26(1), 57-81.

Ishikawa, K. (1976). Guide to quality control. Asian Productivity Organization.

Ishlkawa, K. (1985). What is total quality control? - the Japanese way. (translated by D.J. Lu), NJ:Prentice-Hall.

Juran, J.M. (1979). Quality control handbook, (3rd ed). New York, McGrawHill Book Company.

Juran, J.M. (1988). Juran On planning for quality. New York, The Free Press.

Oakland, J.S. (1989). Total quality management. Oxford, Heinemann Professional Publishing Ltd.

Pugliesi, K. (1999). The consequences of emotional labor: Effects on work stress, job satisfaction, and well-being. Motivation and emotion, 23(2), 125-154.

Rich, B. L., Lepine J. A., ve Crawford, E. R.. (2010). Job engagement: Antecedents and effects on job performance. Academy of Management Journal, 53(3), 617-625.

Ryff, C. D. (1995). Psychological well-being in adult life. Current Directions in Psychological Science, 4, 99-104.

Samman, E. (2007). Psychological and subjective well-being: A proposal for internationally comparable indicators. Oxford Development Studies, 35(4), 459-486.

Schaufeli, W. B., Salanova, M., González-Romá, V., ve Bakker, A. B. (2002). The measurement of engagement and burnout: A two sample confirmatory factor analytic approach. Journal of Happiness Studies, 3(1), 71-92.

Schumacker, R. E., ve Lomax, R. G. (2010). A beginner's guide to structural equation modeling. New York: Routledge. .

Seligman, M. E. (2002). Positive psychology, positive prevention, and positive therapy. Handbook Of Positive Psychology, 2, 3-12.

Seligman, M. E., ve Csikszentmihalyi, M. (2014). Positive psychology: An introduction. In Flow And The Foundations Of Positive Psychology (p. 279-298). Netherlands:Springer 
Shimazu, A., ve Schaufeli, W. B. (2009). Is workaholism good or bad for employee well-being? The distinctiveness of workaholism and work engagement among Japanese employees. Industrial Health, 47(5), 495-502.

Shimazu, A., Schaufeli, W. B., Kamiyama, K., ve Kawakami, N. (2015). Workaholism vs. work engagement: The two different predictors of future well-being and performance. International Journal Of Behavioral Medicine, 22(1), 18-23.

Snyder, C. R., Lopez, S. J., ve Pedrotti, J. T. (2010). Positive psychology: The scientific and practical explorations of human strengths. Sage Publications.

Wright, T. A., Cropanzano, R., ve Bonett, D. G. (2007). The moderating role of employee positive well being on the relation between job satisfaction and job performance. Journal of Occupational Health Psycho$\log y, 12(2), 93-104$.

Zapf, D. (2002). Emotion work and psychological well-being: A review of the literature and some conceptual considerations. Human Resource Management Review, 12(2), 237-268.

\section{Kaynakça Bilgisi / Citation Information}

Arıkan, S. ve Çankır, B. (2019). Gıda ve finans sektöründe çalışan performansı hangi faktörlerden etkileniyor? Sürdürülebilir kalite algısı, psikolojik iyi oluş ve çalışmaya tutkunluk değişkenlerinin rolü. OPUS-Uluslararası Toplum Araştırmaları Dergisi, 12(18. UİK Özel Say1s1), 462-483. DOI: 10.26466/opus.583821. 